\title{
ДОСТИЖЕНИЕ УСТОЙЧИВОГО КОНКУРЕНТНОГО ПРЕИМУЩЕСТВА НА ОСНОВЕ ИНТЕГРИРОВАННОЙ СТРАТЕГИЧЕСКОЙ МОДЕЛИ УПРАВЛЕНИЯ ПРОЕКТАМИ
}

\section{ACHIEVING A SUSTAINABLE COMPETITIVE ADVANTAGE BASED ON AN INTEGRATED STRATEGIC PROJECT MANAGEMENT MODEL}

Yu. Shedko

Summary: The paper substantiates that effective project management can be turned into a competitive advantage, which is achieved when they are aligned with the organizational strategy. The organizational capabilities of an economic entity, which must be taken into account in the strategic planning of a project to ensure a sustainable competitive advantage, have been determined. It is shown that the strategic project management approach provides a mechanism for defining and measuring different levels of project management by integrating nine areas of project management knowledge with five project stages within a consolidated framework based on maturity models. The reasons for resistance to the implementation of project management are highlighted. The stages of strategic planning of project management are detailed.

Keywords: project management, strategic planning; sustainable development strategy; competitive advantages project life cycle. $\ni$ ффективное стратегическое планирование проекта имеет важное значение для долгосрочного успеха и неудачи для любой организации. Повышение эффективности управления проектами, особенно инновационными проектами должно ускорить модернизацию национальной экономики, что является одним из важнейших условий успешной структурной трансформации экономики. Важно изменить подходы к управлению проектами, внедрить превентивное управление, с учетом требований экономической и экологической безопасности [3], обеспечения реализации политики импортозамещения [6]. При этом стратегическое планирование проекта для обеспечения устойчивого конкурентного преимущества организации должно использовать экономические и математические инструменты и новые информационные технологии [9], учитывать организационные возможности, такие как взаимодействие между членами проектной команды, руководством и сотрудниками из различных бизнес-подразделений, а также роли различных заинтересованных сторон, а также корпоративную структуру и корпоративную культуру. Кроме того, перспективы развития карьеры для всех руководителей проектов в организации играет роль в высокой
Шедько Юрий Николаевич

д.э.н., дочент, ФГОБУ ВО «Финансовый университет при Правительстве Российской Федерации», Москва ynshedko@mail.ru

Аннотация: В работе обосновывается, что эффективное управление проектами возможно превратить в конкурентное преимущество, которое достигается при согласовании их с организационной стратегией. Определены организационные возможности хозяйствующего субъекта, которые надо учитывать при стратегическом планировании проекта для обеспечения устойчивого конкурентного преимущества. Показано, что стратегический подход к управлению проектами обеспечивает механизм для определения и измерения различных уровней управления проектами путем интеграции девяти областей знаний по управлению проектами с пятью этапами проекта в рамках консолидированной схемы с учетом моделей зрелости. Выделены причины сопротивления внедрению управления проектами. Детализированы этапы стратегического планирования управления проектами.

Ключевые слова: управление проектами, стратегическое планирование; стратегия устойчивого развития; конкурентные преимущества, жизненный цикл проекта.

эффективности компании в области стратегического управления проектами.

Стратегическое управление проектами - это комплексный подход к достижению устойчивого конкурентного преимущества, получаемого путем согласования стратегических бизнес-целей со стратегией управления проектами.

Таким образом, стратегическое управление проектами является жизненно важным для организации способом соединения стратегического управления и оперативного управления, поскольку оно определяет процессы, посредством которых организация адаптируется к постоянно меняющейся среде. Таким образом, реализация стратегии следует за принятием организационных политик и практик, которые соответствуют корпоративной стратегии. Кроме того, разработка стратегии, которая должна быть действенной, включает следующее:

- определение организационных структур, процессов и отношений для достижения выдающихся результатов в бизнесе; 
- достижение успеха за счет превосходства в таких ресурсных областях организации, как человеческие ресурсы, информационные технологии, финансы и т.д.

Стратегическое планирование управления проектами требует разработки стандартной методологии стратегического управления проектами. Разработка этой методологии обеспечивает последовательность ключевых действий для организации. Кроме того, управление интеграцией проектов играет ключевую роль в работе с растущим числом взаимосвязанных функциональных подразделений в организациях.

Стратегический подход к управлению проектами обеспечивает механизм для определения и измерения различных уровней управления проектами путем интеграции девяти областей знаний по управлению проектами с пятью этапами проекта в рамках консолидированной схемы с учетом моделей зрелости [8]. Жизненный цикл проекта состоит из пяти этапов: 1) инициирование; 2) планирование; 3) выполнение; 4) мониторинг и контроль; 5) закрытие. При этом важно убедиться, что этапы стратегического планирования четко согласованы с методологией управления проектами. В аспекте целеполагания анализ, формулирование, реализация и определение стратегических целей должны соответствовать осуществимости.

Основными областями знаний являются:

1. Управление интеграцией проектов объединяет и координирует процессы и действия в каждой группе процессов. Таким образом, эффективная реализация приводит к заявленным целям, планам действий, графикам, политикам и процедурам.

2. Управление рисками проекта предназначено для идентификации, анализа, планирования, реагирования и контроля рисков в проекте. Его цель состоит в том, чтобы увеличить вероятность и влияние позитивных событий, и уменьшить вероятность и влияние негативных событий в проекте [2, 7].

3. Управление закупками занимается покупкой или приобретением продуктов, услуг или результатов, необходимых для реализации проекта.

4. Управление масштабом проекта гарантирует, что стратегия сфокусирована, и проект находится в его пределах.

5. Управление временем проекта (краткосрочный, среднесрочный или долгосрочный проекты).

6. Управление стоимостью проекта: стратегия проекта должна быть экономически эффективной или обеспечивать снижение затрат.

7. Управление качеством проекта: качество является дифференциатором. Компании должны соблюдать стандарты качества, даже если качество не является стратегической целью. Компании должны обеспечивать высокие стандарты качества и сводить к минимуму жалобы клиентов в качестве дифференциатора, что, в свою очередь, повлияет на доверие инвесторов.

8. Управление человеческими ресурсами проекта: люди - самый важный ресурс в проекте [5].

9. Управление коммуникациями проекта: менеджеры проекта должны сосредоточиться на понимании коммуникационных потребностей каждого сотрудника, участвующего в проекте.

Отметим, что при анализе влияния офиса управления проектами основными областями риска являются численность персонала, производительность членов команды, бюрократия, организационная реструктуризация.

Реализация стратегии связана с отношениями между управлением проектами, управлением знаниями и стратегическим портфелем проектов. Организации, в которых организационная архитектура соответствует стратегии, являются менее уязвимыми к внешним факторам и внутренним слабостям, достигая лучших результатов. Следовательно, решения руководства, касающиеся приоритетов портфеля и капитальных затрат, должны учитывать общий контекст, включающий как внешние, так и внутренние факторы бизнеса. Кроме того, проекты используют организационную структуру и являются частью инфраструктуры фирмы.

Стратегия проекта должна признавать автономность проекта, а также его уникальную позицию как часть его сложного контекста.

Стратегическое управление проектами включает в себя серию практик, процедур, процессов, инструментов и поведений, которые определяют, как организации получают выгоду от взаимодействия между управлением проектами и бизнес-практиками - и все это во имя достижения общих стратегических целей организации. При этом стратегия - это и комплексный набор действий или действий, которые направляют и направляют использование ресурсов фирмы для достижения видения и целей организации и обеспечивают устойчивое конкурентное преимущество. Кроме того, стратегическое планирование - это процесс управления путем формулирования и реализации решений о будущем пункте назначения организации. Кроме того, стратегическое управление проектами состоит из управления проектами, направленными на развитие организационных компетенций и способностей, которые способствуют устойчивому конкурентному преимуществу организации.

В текущем организационном контексте и культуре, характеризуемой ускоренными изменениями, руково- 
дители проектов должны адаптироваться к большим потокам зачастую противоречивой информации. Поэтому руководителям программ приходится одновременно иметь дело с высокой неопределенностью.

Интегрированная стратегическая модель управления проектами помогает организации достичь устойчивого конкурентного преимущества, предоставляя руководителям программ стратегии для достижения эффективности в реализации видения. В этом контексте члены команды считают свой вклад значимым, и высшее руководство чувствует, что контролирует происходящее. В то же время подход к управлению проектами обеспечивает требуемые KPI (ключевые показатели эффективности) для взаимодействия со стратегическими методологиями реализации, такими как карта сбалансированных показателей.

Компании, ищущие устойчивое конкурентное преимущество, получат выгоду от использования этой модели, которая в конечном итоге направлена на развитие скрытых знаний в организации. Этапы, оценка, воображение и осмысление способствуют процессу обучения Такой гибкий подход позволит организации эффективно передавать инициативы высшего руководства исполнительной группе. Этот подход создает ценность и позволяет быстро вносить коррективы, поскольку группа процессов мониторинга и контроля постоянно проверяет достижения качества.

Рассмотрим разработку стратегии как процесс принятия решения по поводу понимания сущности бизнеса и поддержания его конкурентоспособности на рынке.

Выделим ряд причин сопротивления внедрению управления проектами, которые заставляют руководителей бояться перемен:

- децентрализация власти: если бы управление проектами было основной компетенцией, потребовалось бы, чтобы высшие руководители делегировали принятие решений руководителям проектов, что уменьшит их власть и влияние;

- отдельные руководители не могут понять выгоды, которые может принести управление проектом, так как считают, что оно относится к операционному уровню;

Как только организация устанавливает стратегические основы и свои возможности управления проектами, она должна планировать стратегическое управление проектами.

Формулирование стратегии в данном контексте включает в себя следующее:

- изучение внешней и отраслевой среды;
- интерпретация экологических изменений для выявления возможностей и угроз;

- сканирование внутренней среды;

- определение основной компетенции организации и текущего уровня бизнеса, а также стратегии корпоративного уровня;

- достижение устойчивого конкурентного преимущества путем выработки миссии и видения организации путем тщательного сопоставления сильных и слабых сторон внутренних ресурсов с экологическими возможностями и угрозами;

- постановка целей для реализации миссии, исходя из перспективы руководства и результатов предыдущих шагов. Высшее руководство сталкивается с необходимостью принятия правильных стратегических инвестиционных решений. Многие процессы принятия стратегических решений по поводу внедрения инноваций по оказались успешными в определении и выборе стратегических проектов [1, 4].

Стратегическое планирование управления проектами предусматривает ряд этапов: постановка целей, анализ, разработка стратегии, реализация стратегии и мониторинг, оценка и контроль.

\section{Постановка челей}

Цель этапа - прояснить видение бизнеса. Постановка цели состоит из определения трех ключевых аспектов:

- Постановка краткосрочных и долгосрочных целей.

- Определение процесса достижения целей.

- Адаптация процесса для базы сотрудников и распределение обязанностей.

- Написание миссии, в которой сообщается о целях.

- Наконец, организация должна выполнить проверку реальности, чтобы удостовериться, что цели достижимы, ценности организации совпадают, и есть вклад в видение.

Этап анализа включает в себя систематическое изучение и оценку собранных данных, разделение их на группы, чтобы выявить их взаимосвязь друг с другом и понять причинно-следственные связи, влияющие на стратегию, тем самым обеспечивая основу для решения проблем и принятие решения. Это ключевой этап, потому что информация, полученная на этом этапе, будет формировать следующие два этапа. Кроме того, в центре внимания анализа должно быть понимание потребностей бизнеса для достижения устойчивого конкурентного преимущества. Анализ должен помочь установить стратегическое направление и определить стратегические инициативы, которые помогут бизнесу расти. Не менее важно выявить любые внешние или внутренние проблемы, которые могут ограничить достижение целей и задач. 


\section{Формулирование стратегии}

Первым шагом в формировании стратегии является анализ информации, чтобы определить ресурсы, на которые бизнес рассчитывает в данный момент, и какие из них могут помочь в достижении определенных целей и задач. Затем высшее руководство должно определить любые области, в которых бизнес должен искать внешние ресурсы. Кроме того, компания должна уделять приоритетное внимание тем проблемам, с которыми сталкиваются их важность и вклад в корпоративную стратегию; как только это будет сделано, разработка стратегии может начаться. Таким образом, анализ чувствительности поможет в определении возможных сценариев.

\section{Реализашия стратегии}

С одной стороны, успешная реализация стратегии является ключом к успеху любого бизнеса. С другой стороны, реализация стратегии составляет этап действия процесса стратегического управления. Более того, могут потребоваться серьезные изменения, если общая стратегия не соответствует текущей структуре бизнеса, поэтому следует разработать новую структуру. Каждый сотрудник организации должен знать о своих обязанностях и обязанностях, а также о том, как они способствуют достижению общей цели.

Заключительным этапом в стратегическом планиро- вании является мониторинг, оценка и контроль. Стратегические действия по оценке и контролю включают разработку ключевого показателя эффективности (KPI), измерение эффективности и сравнительный анализ, чтобы определить, соответствует ли выбранная стратегия целям организации. Основными видами деятельности на этом этапе являются:

- установление базовой линии для внутренних и внешних факторов в текущей стратегии;

- проведение измерения производительности;

- предпринимать корректирующие действия.

Если вышеупомянутые действия не являются успешными, то процесс стратегического управления должен быть повторен.

Таким образом, можно отметить, что проекты - это инструменты, используемые для реализации стратегии развития. Стратегии могут быть разбиты на тактики, которые затем могут быть реализованы в виде программ. И, следовательно, проекты будут относиться к определенной стратегической программе. Поэтому в любой организации должна быть возможность проследить проекты до конкретных организационных целей. Интегрированная модель стратегического управления проектами может внести вклад в преодоление разрыва между подходом управления проектом и реализацией стратегии.

\section{ЛИТЕРАТУРА}

1. Борисовская Т.А. Научно-технический прогресс и теория устойчивого развития / Т.А. Борисовская, Г.А. Аминова // Научные труды Вольного экономического общества России. 2008. Т. 103. С. 56-62

2. Власенко М.Н. Управление рисками в системе экономической безопасности региональных объектов промышленности М.Н. Власенко, Ю.Н. Шедько // Россия в XXI веке: глобальные вызовы и перспективы развития: Материалы Шестого Международного форума (21-22 декабря 2017 г.). Москва, ИПР РАН, 2017. - С. 412-420

3. Власенко М.Н. Экономическая безопасность и ее экологическая составляющая - значимый фактор устойчивого развития предприятий в условиях современного рынка / М.Н. Власенко, Ю.Н. Шедько // Стратегии бизнеса. 2017. № 2 (34). С. 21-24.

4. Государственная инновационная политика в Российской Федерации: Монография / Под ред. С.Е. Прокофьева, О.В. Паниной - М.: Издательство «Спутник $+», 2018 .-234$ c.

5. Методы и инструменты материального и материального стимулирования участников проектной деятельности в государственных органах исполнительной власти: монография // Под редакцией Прокофьева С.Е. и Паниной 0.В.// Общество с ограниченной ответственностью «Центркаталог», 2019. - 192 с.

6. Миндлин Ю.Б., Тихомиров Е.А. Организация импортозамещения в отечественном АПК на основе расширенных агропромышленных производственных цепочек // Современная наука: актуальные проблемы теории и практики. Серия «Экономика и право». -2017. - № 4. - С. 35-41.

7. Пожидаева Е.С. Контроль рисков предприятия в рамках функций внутреннего аудита предприятия / Е.С. Пожидаева // В сборнике: Актуальные проблемы учета, анализа, контроля и налогообложения в условиях цифровизации экономики. Межвузовский сборник научных трудов и результатов совместных научно-исследовательских проектов, представленных на 4-й международной научно-практической конференции. Москва, 2020. С. 49-52.

8. Трифонов П.В. Анализ управления проектами посредством моделей зрелости / П.В. Трифонов, А.М. Узбекова // Экономика и управление: проблемы, решения, 2017. - № 3. - Т.2.- С.127-132

9. Shubtsova L.V., Komov V.E., Zudenkova S.A., Sokolova A.P., Gozalova E.A., Ukhina T.V., Doronkina I.G. Project management of organizations // International Journal on Emerging Technologies. 2019. -- T. 10. - № 3. -C. 332-336. 